\title{
LA CADENA DE VALOR DEL CACAO EN PERÚ Y SU OPORTUNIDAD EN EL MERCADO MUNDIAL*
}

Recibido: 8 de septiembre de 2014 Aprobado: 20 de agosto 2015

\author{
Pedro Barrientos Felipa**
}

RESUMEN

El objetivo de este trabajo es describir las características de la cadena de valor del cacao en Perú. Para ello se realiza un estudio de tipo documental que relata el desempeño de los mercados de comodities agrarios, la comercialización de estos, el funcionamiento de la cadena en el País y la explicación de la estrategia nacional para este producto. Como resultado se plantea que el contexto en que se desarrolla el cacao peruano presenta ventajas debido a los problemas que tienen los productores en África, el potencial del mercado internacional con la inclusión de China e India, y el apoyo que el Estado está brindando a los pequeños productores, lo que debe ser aprovechado a través de la formación de cadenas de valor.

\section{PALABRAS CLAVE:}

Cacao, mercado de materias primas, productos agrícolas, marketing, Perú

\section{CLASIFICACIÓN JEL}

M31, M16, QO2, Q13

\section{CONTENIDO}

Introducción; 1. El mercado de los commodities en Perú; 2. Los Commodities agrarios en el Perú; 3. El mercado y la cadena de valor del cacao peruano; 4. La comercialización mundial del cacao; 5. La cadena del cacao en el Perú; 6. Los principales actores en la cadena de valor del cacao peruano; 7 . Las características de la producción local; 8. El cacao en la estrategia nacional; 9. Conclusiones; Bibliografía.

* Este artículo es producto de la investigación "La producción de cacao y su efecto en la comercialización internacional", realizada para el Instituto de Investigaciones Económicas de la Universidad Nacional Mayor de San Marcos en el período 2013-2014.

** Economista, Universidad Ricardo Palma, Lima, Perú. Magíster en Administración, Universidad del Pacífico, Lima, Perú. Doctor en Administración de Negocios Globales, Universidad Ricardo Palma, Lima, Perú. Director de la Escuela de Economía Internacional, profesor principal y miembro del Instituto de Investigaciones Económicas de la Facultad de Ciencias Económicas, Universidad Nacional Mayor de San Marcos, Lima, Perú. Correo electrónico: pbarrientosf@unmsm.edu.pe. 


\section{THE COCOA VALUE CHAIN IN PERU AND ITS OPPORTUNITIES IN THE GLOBAL MARKET ABSTRACT}

The objective of this paper is to describe the characteristics of the cocoa value chain in Peru. For this, a documental type of study is carried out which describe the performance of the agricultural commodity markets, the commercialization of these, the way the value chain works in the country and an explanation of the national strategy for this product. The result suggests that the context under which the Peruvian cocoa is developing has its benefits given the problems being faced by African producers, the potential in the global market with China's and India's inclusion and the support given by the Government to small holders, which should be used during the formation of value chains.

\section{KEY WORDS}

Cocoa, commodity markets, agricultural markets, marketing, Peru

\section{JEL CLASSIFICATION}

M31, M16, QO2, Q13

\section{CONTENT}

Introduction; 1. Commodity market in Peru; 2. Agricultural commodities in Peru; 3. The market and the cocoa value chain in Peru; 4. International commercialization of cocoa; 5. Cocoa value chain in Peru; 6. Main stakeholders in the Peruvian cocoa value chain; 7 . Local production characteristics; 8 . Cocoa as part of the national strategy; 9. Conclusions; Bibliography.

\section{A CADEIA DE VALOR DO CACAU NO PERU E SUA OPORTUNIDADE NO MERCADO MUNDIAL \\ RESUMO}

O objetivo deste trabalho é descrever as características da cadeia de valor do cacau no Peru. Para isso se realiza um estudo de tipo documental que relata o desempenho dos mercados de commodities agrários, a comercialização destes, o funcionamento da cadeia no País e a explicação da estratégia nacional para este produto. Como resultado se planteia que o contexto no qual se desenvolve o cacau peruano apresenta vantagens devido aos problemas que têm os produtores na África, o potencial do mercado internacional com a inclusão da China e da Índia, e o apoio que o Estado está brindando aos pequenos produtores, o que deve ser aproveitado através da formação de cadeias de valor.

\section{PALAVRAS CHAVE}

Cacau, Peru, Mercado de matérias primas e marketing, Produtos agrícolas.

\section{CLASSIFICAÇÃO JEL}

M31, M16, QO2, Q13

\section{CONTEÚDO}

Introdução; 1. O mercado das commodities no Peru; 2. As Commodities agrários no Peru; 3. O mercado e a cadeia de valor do cacau peruano; 4 . A comercialização mundial do cacau; 5.A cadeia do cacau no Peru; 6. Os principais atores na cadeia de valor do cacau peruano; 7. As características da produção local; 8. O cacau na estratégia nacional; 9. Conclusões; Bibliografia. 


\section{INTRODUCCIÓN}

El cacao, como insumo para producir chocolate es apreciado al nivel mundial por su sabor y sus beneficios nutritivos. Esta importancia lo convierte en un producto de demanda significativa, que debido a sus diversas presentaciones es accesible a todo tipo de público. La comercialización del cacao es influida por la demanda de productores de chocolate que se ubican en Europa -los más importantes-a pesar de que este fruto es de origen americano. La demanda del producto lleva a que su cultivo se expanda en tres continentes: África, Asia y América. La potencialidad es expectante, al integrarse a la cadena de consumo países emergentes como China e India.

En Perú se produce de una manera ordenada y competitiva desde inicios del siglo XXI. Tal situación permite una mejor articulación económica entre los productores y el mismo mercado local, influyendo en su integración al mercado global que cada día requiere productos -elaborados con cacaos especiales- más sofisticados. Es un mercado dispuesto a pagar mejores precios, con respecto a los que se cotizan en las bolsas de valores más importantes, como la de Nueva York y Londres.

El crecimiento de la producción del cacao se ha convertido en algunas localidades de Perú en una importante fuente de ingresos de los productores, mejorando así el producto interno bruto (PIB) de la región. Este esfuerzo permite que estos se integren, directa o indirectamente, al mercado internacional. Esta situación de rápido crecimiento, considerando que la mayoría de productores son pequeños, asume en su interior la cuestión de la sostenibilidad económica. Los territorios de clima tropical, desde San Martín hasta Puno, son ideales para el cultivo de cacao. Para 2014, el Perú produce más de 30 mil toneladas de cacao. Sin embargo, su potencial de producción y demanda es expectante, motivo por el cual el cultivo debe ser sostenible en el tiempo y ahí debe concentrarse el esfuerzo.

El diseño de cualquier estrategia de comercio internacional debe considerar que la producción local se basa en el esfuerzo de pequeños agricultores, que se convierten en parte importante de una cadena de valor. En el sistema de producción, cuando se trata de la economía sostenible del cacao, se refiere a que la cadena de producción tenga permanencia en el tiempo, de manera que tanto vendedores como compradores, incluyendo los prestadores de servicios, puedan satisfacer sus necesidades o expectativas sin tener un perjuicio entre ellos. Tal permanencia debe traducirse en una mejora de aspectos sociales de los productores (salud, alimentación, educación), protección del medio ambiente en que se desarrolla el cultivo y mejora del bienestar económico de los productores. 
El objetivo del estudio se concentra en describir las características de la cadena de valor del cacao en la economía peruana. La metodología utilizada es de tipo documental donde se muestra el desempeño y comercialización de los comodities agrarios, la estructura y funcionamiento de la cadena de valor y la estrategia nacional para este producto. Los resultados reflejan que la producción y comercialización del cacao posee ventajas que se deben, en particular, a los problemas que tienen los productores de África, el potencial que del mercado que se tiene con India y China y el apoyo estatal a los pequeños productores, hechos que deben ir encaminados a la formación de cadenas de valor.

El trabajo se divide en siete secciones tituladas así: el cacao en el mercado de los commodities, los commodities agrarios en el Perú, la comercialización mundial del cacao, la cadena del cacao en el Perú, los principales actores de la cadena de valor del cacao en el Perú, las características de la producción local y el cacao en la estrategia nacional. Finalmente se presentan las conclusiones de la investigación.

\section{EL MERCADO DE LOS COMMODITIES EN PERÚ}

Los productos que tienen una mayor participación en el PIB peruano son los productos primarios. Estos productos tradicionales representan el $75.0 \%$ del total de las exportaciones y son conocidos como materias primas básicas, se extraen de la naturaleza, tienen poco valor agregado y en el país de destino es donde se les agrega valor o se transforman, lo que genera al transformador un mayor beneficio. A estas materias primas también se les conoce como commodities.

Colburn (2009, p. 44) menciona que los países de América Latina son prisioneros de los commodities, especialmente de los metales, quienes han presentado en la década anterior (primera década del siglo XXI) un comportamiento alcista de sus precios. La mejora que ha habido en las economías es influida por lo que ha ocurrido con los precios de los commodities, lo cual es un riesgo en el momento en que estos comiencen a descender y se detenga el crecimiento económico.

Respecto a China, que se considera un mercado potencial para el cacao, Jenkins (2011, p. 77) manifiesta que "entre los años 2002 y 2008, el auge de los precios de los productos básicos hizo que aumentaran notablemente los ingresos derivados de las exportaciones de América Latina, en parte debido al incremento de la demanda china de esos productos". Hoy en día el análisis económico de los países, importadores y exportadores, debe considerar la repercusión de lo que produce y consume China. América Latina ha sido favorecida, especialmente Perú, quien ha afianzado su relación comercial con China. El principal riesgo es que esto se haga basándose en commodities. Al respecto, De la Torre (2011, p. 14) expone que: 
La cadena de valor del cacao en Perú y su oportunidad en el mercado mundial

El tema de fondo es si América Latina se está convirtiendo en el granero y mina de China sin que ellos repercutan positivamente sobre el crecimiento de largo plazo de la región. En este sentido, algunos autores de la CEPAL alertan acerca de que la región se está integrando al polo de desarrollo del siglo XXI (China) con una estructura productiva del siglo XIX (concentrada en materias primas).

En el mismo sentido Jenkins (2011, p. 85) plantea:

La influencia del aumento de la demanda china en los precios mundiales de diversos productos básicos no solo depende del tamaño de la repercusión de la demanda, sino que también se ve afectado por la sensibilidad de la oferta mundial al incremento de la demanda y por la existencia, o no, de un mercado mundial integrado del que China forma parte.

En el cuadro 1 se observa la importancia de los productos o commodities mineros en la economía peruana. Del total de exportaciones que se realizaron, a fines del 2012, el $56.8 \%$ corresponden a productos mineros, siendo el 2010 el año de mayor valor relativo (62.1\%). Su importancia en los últimos 10 años normalmente ha superado el $50 \%$ del total exportado. La caída de los precios de los metales influye en el valor de las exportaciones y afecta a la economía nacional. Como lo argumenta Colburn (2009, p. 49):

Ahora que los precios han caído, la economía peruana está en peligro. Tanto los líderes del sector privado como los gobernantes peruanos tienen que encontrar formas de evitar que el país caiga en serios problemas. Ahora, más que nunca, Perú y todos los demás países de América latina requieren un manejo inteligente y ágil de sus economías. Es el momento para nuevas formas de pensar.

Cuadro 1. Exportaciones del Perú por grupo de productos (porcentajes)

\begin{tabular}{|l|c|c|c|c|c|c|c|c|c|c|}
\hline \multicolumn{1}{|c|}{ Sector } & 2003 & 2004 & 2005 & 2006 & 2007 & 2008 & 2009 & 2010 & 2011 & 2012 \\
\hline Pesqueros & 9.0 & 8.6 & 7.5 & 5.6 & 5.2 & 5.8 & 6.2 & 5.3 & 4.5 & 5.0 \\
\hline Agrícolas & 2.5 & 2.5 & 1.9 & 2.4 & 1.6 & 2.2 & 2.4 & 2.7 & 3.6 & 2.4 \\
\hline Mineros & 51.6 & 55.6 & 56.4 & 61.8 & 62.1 & 58.4 & 60.8 & 61.1 & 59.1 & 56.8 \\
\hline Petróleo y gas natural & 6.8 & 5.0 & 8.8 & 7.6 & 8.2 & 8.6 & 7.1 & 8.7 & 10.2 & 10.9 \\
\hline TRADICIONALES & 69.9 & 71.7 & 74.6 & 77.4 & 77.1 & 75.0 & 76.5 & 77.8 & 77.5 & 75.1 \\
\hline NO TRADICIONALES & 28.8 & 27.2 & 24.6 & 22.2 & 22.5 & 24.4 & 22.9 & 21.5 & 21.9 & 24.2 \\
\hline OTROS & 1.3 & 1.1 & 0.8 & 0.4 & 0.4 & 0.6 & 0.6 & 0.7 & 0.7 & 0.7 \\
\hline TOTAL & 100.0 & 100.0 & 100.0 & 100.0 & 100.0 & 100.0 & 100.0 & 100.0 & 100.0 & 100.0 \\
\hline
\end{tabular}

Fuente: Tomado de BCRP (2012). Anexo 37 
Esta dependencia en los commodities y precios que tuvieron los países latinoamericanos en la primera década del siglo XXI explican que la crisis no haya afectado significativamente a los países latinoamericanos exportadores de materias primas. Para De La Torre (2011, p. 14):

Esto nos permite explicar claramente por qué en la crisis reciente, la mayor parte del 2008 (en los meses previos de Lehman Brothers) cuando los países ricos empezaban a entrar en recesión, Latinoamérica se desacopló y pudo mantener un crecimiento fuerte. La razón fue que, justamente, los precios de los commodities se encontraban en pleno auge ${ }^{\prime \prime}$.

Svampa (2013) hace una acotación importante a la dinámica económica del proceso de los commodities, a través del concepto "Consenso de los commodities" como un comportamiento novedoso en este mercado que implica el establecimiento de megaproyectos tendentes al control, la extracción y la exportación de bienes naturales, sin mayor valor agregado, lo que implica que hay un esfuerzo para seguir en esta vía, la poca industrialización del país. Es como optar por el pensamiento de "este es nuestro destino". En opinión de Svampa (2013, p.12) y bajo el nuevo contexto:

[...] la demanda de commodities ha originado un importante proceso de reprimarización de las economías latinoamericanas, al acentuar la reorientación de estas hacia actividades primarias extractivas o maquilas, con escaso valor agregado. Esta dinámica regresiva se ve agravada por el ingreso de potencias emergentes, como es el caso de China, país que de modo acelerado se va imponiendo como un socio desigual en lo que respecta al intercambio comercial con la región.

\section{LOS COMMODITIES AGRARIOS EN EL PERÚ}

Los principales commodities agrícolas que se producen en el Perú son el algodón, el azúcar y el café (Cuadro 2). El cacao también es parte del mercado internacional de los commodities, pero por volumen de producción no ocupa un lugar importante en la economía peruana. El volumen que se exporta de algodón, es bajo, lo que puede deberse a que los productores tienen productos agrícolas con mejor rendimiento. El precio del azúcar también mejora en el mercado internacional: en el año 2012 tiene un volumen exportable 8.4 t m. El azúcar tiene buenos años (2006, 2010); su comportamiento en los últimos años está influido porque parte de la producción está canalizada a la producción de etanol. Tanto el algodón como el azúcar son productos que se ubican en la zona costera, contrario a lo que ocurre con el café que necesita áreas de altura. El café ha tenido un comportamiento sostenido, siendo su mejor año de producción el 2011, cuando el precio por t m llegó a US\$ 5,382.40.

1 Según el diario El País (2013), el banco Lehman Brothers se declaró en quiebra en septiembre del 2008. 
La cadena de valor del cacao en Perú y su oportunidad en el mercado mundial

Cuadro 2. Exportaciones de productos tradicionales agrícolas en Perú, 2005-2012

\begin{tabular}{|l|c|c|c|c|c|c|c|c|}
\hline & 2005 & 2006 & 2007 & 2008 & 2009 & 2010 & 2011 & 2012 \\
\hline Algodón (Millones de US\$ FOB) & 3.3 & 7.1 & 3.2 & 2.3 & 2.7 & 1.1 & 7,8 & 4.5 \\
\hline Volumen (miles tm*) & 2.0 & 3.8 & 1.5 & 0.9 & 1.6 & 0.5 & 2.1 & 1.9 \\
\hline Precio (US\$/tm) & 1.640 .4 & 1.833 .2 & 2.093 .6 & 2.505 .2 & 1.722 .0 & 2.417 .9 & 3.762 .2 & 2.404 .7 \\
\hline Azúcar (Millones de US\$ FOB) & 12.7 & 43.1 & 18.8 & 24.7 & 37.1 & 64.7 & 47.6 & 5.8 \\
\hline Volumen (miles tm) & 32.2 & 108.5 & 48.3 & 70.4 & 85.5 & 112.0 & 62.6 & 8.4 \\
\hline Precio (US\$/tm) & 395.1 & 395.7 & 388.9 & 350.9 & 433.2 & 577.9 & 759.9 & 690.4 \\
\hline Café (Millones de US\$ FOB) & 307 & 515 & 427 & 645 & 584 & 888 & 1,581 & 1,009 \\
\hline Volumen (miles tm) & 142.2 & 238.1 & 173.6 & 225.1 & 197.7 & 229.8 & 293.7 & 262.7 \\
\hline Precio (US\$/tm) & $2,57.0$ & $2,163.3$ & $2,459.0$ & $2,865.9$ & $2,956.7$ & $3,864.7$ & $5,382.4$ & $3,842.2$ \\
\hline
\end{tabular}

Nota: Tm: Toneladas métricas

US\$̦: Dólares de Estados Unidos de América.

Fuente: Tomado de BCRP (2012) anexo 38

Se observa, en relación con el cuadro 2, que el único commodity agrícola que muestra un desarrollo importante es el café, sobre el cual -en el país- se están desarrollando estrategias diferenciadoras impulsadas por el Estado y el aporte del sector privado local y extranjero.

Castro y Contreras (2004) identifican un nicho de mercado rentable para el café peruano, el de especialidad, lo que debe ser considerado -como estrategia de marketing internacional- también para el cacao. Para acceder a este mercado debe considerarse un café de la más alta calidad, producido en microclimas geográficos específicos, tener un sabor particular y ser extraído siguiendo estándares rigurosamente establecidos. Los investigadores citados mencionan que Perú cuenta con ventajas comparativas para obtener café de especialidad porque tiene una de las mejores variedades botánicas de café (coffea arabica), condiciones climáticas y geográficas adecuadas, y disponibilidad de agua en zonas tropicales de altura. Los hechos recientes demuestran que tal enunciado se está cumpliendo y Perú está ocupando un lugar destacado en este tipo de café.

\section{EL MERCADO Y LA CADENA DE VALOR DEL CACAO PERUANO}

En el mercado internacional la producción peruana de cacao recién está apareciendo en las estadísticas (ICCO, 2012), lo que por el momento no permite avizorar -ni en 
el corto, ni en el largo plazo- lo que se denomina la enfermedad holandesa. En esta última idea se toma en cuenta lo expresado por Ocampo (2005, p. 8):

La "Enfermedad Holandesa" tiende a reducir a largo plazo el nivel total de exportaciones o cambiar la composición de las mismas. El incremento de las exportaciones del recurso natural abundante desvía exportaciones de la manufactura y los servicios, sectores favorables para impulsar el crecimiento económico. El recurso natural puede además atraer recursos del exterior como la inversión extranjera, la tecnología y el "know how" en desmedro de otros sectores. La dependencia de exportaciones de bienes primarios hace más vulnerable a una economía, frente a la alternativa de una economía manufacturera. Esto debido a la mayor volatilidad de los precios de los bienes primarios que de las manufacturas en los mercados internacionales. Se produce entonces una erosión de la habilidad de competir en los mercados mundiales, reduciendo la posibilidad de crecimiento económico en el largo plazo.

Nadurille (2010) expone que el cacao representa la fuente de ingreso principal de 40 a 50 millones de personas en el mundo en zonas de producción ubicadas en África, Asia, Centro y Sudamérica. África se destaca en la producción, siendo Costa de Marfil el país con casi el 50 \% del total mundial. En Asia, países como Indonesia presentan crecimientos acelerados, siendo las políticas gubernamentales las que promueven la expansión de las áreas dedicadas a este cultivo.

La producción de cacao está altamente concentrada en unos pocos países no desarrollados. Según la ICCO (2012, p. 32), los principales productores en el ámbito mundial en el período 2012 son: Costa de Marfil con $1410 \mathrm{~m}$ t m, Ghana con $890 \mathrm{~m} \mathrm{t}$ m e Indonesia con $500 \mathrm{~m} \mathrm{t} \mathrm{m}$, los tres países produjeron el 86.2 \% del total mundial. En América Latina, los principales productores son Brasil con 190 m t m y Ecuador con 175 m t m; Perú logró 57.9 m t m. Es sencillo, identificar que los principales productores son países en desarrollo, que se caracterizan por un desarrollo básico de su agricultura. La transformación industrial se da en los países desarrollados.

En el gráfico 1 se observa la cadena de provisión, producción y comercialización. Se inicia con los proveedores de insumos, y también se incluye a los financieros por los altos costos del crédito, lo que en ocasiones limita el acceso del pequeño productor. En otros casos, para el financiamiento, son apoyados por las empresas manufactureras y empresas distribuidoras. El caso particular se observa en la división de las empresas manufactureras, ubicándose de dos tipos: 1) de subproductos, en las que se identifican empresas como Cargill, Archer Daniels Midland Company, Bloomer Chocolate Company y World's Finest Chocolate; y 2) procesamiento de productos: Nestlé, Mars, Cadbury, Ferrero Rocher y Harshey's. La influencia de estas empresas llega hasta el manejo del cultivo del cacao, es decir, no solo les interesa la compra, sino que se preocupan en el mismo desarrollo del grano. 
La cadena de valor del cacao en Perú y su oportunidad en el mercado mundial

Gráfico 1: Cadena de provisión, producción y distribución

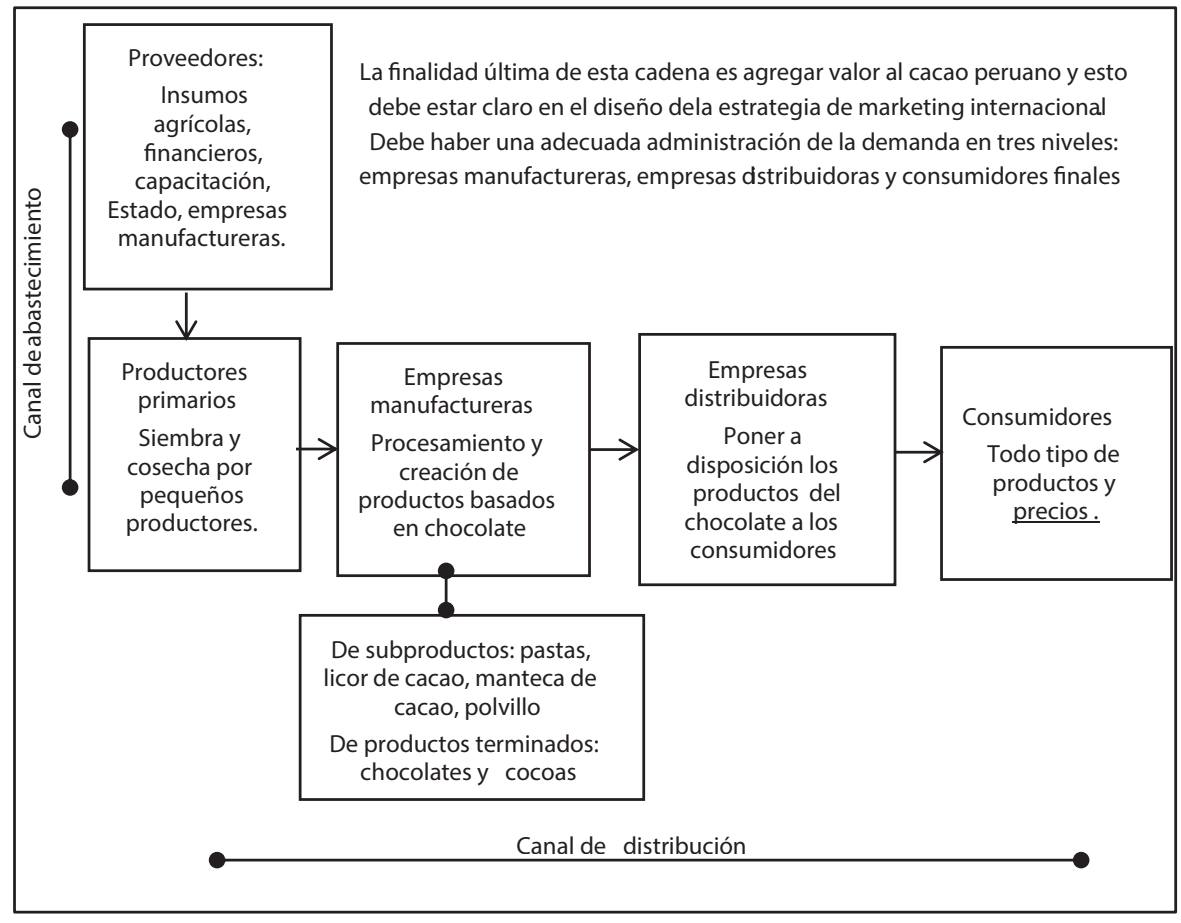

Fuente: elaboración propia

En el comercio internacional existen productos en que no todo se negocia con precios bajos, sino que existen otros factores de los cuales se debe tomar ventaja. Sin embargo, siempre se tiene que estar alerta; de ahí que la innovación es importante, lo que se realiza a través de la investigación. Entonces, para los años posteriores, otro desafío es responder a la pregunta: ¿cómo se puede innovar en la producción de cacao?

De ahí cabe hacer la pregunta ¿cómo puede hacerse más competitiva la industria del cacao peruano? La alternativa es buscar un nuevo tipo de comprador y añadir valor al producto, lo que favorece una estrategia de diferenciación, estableciendo precios más favorables, que el productor considere que al momento de vender su producto (cacao) ya tiene valor añadido, el que está en función de las exigencias de su comprador. Así se fortalece o crea la ventaja competitiva del productor.

Hay mercado potencial para el cacao, particularmente China e India, en donde el consumo tiene una tasa de crecimiento que permite avizorar un sólido crecimiento de la demanda por chocolate. Se estima que los ciudadanos chinos consumen el 5 \% de lo que compra un consumidor europeo. Los hindúes un $25 \%$. Si se mantiene la 
demanda, al menos en el mediano plazo, la demanda superaría la oferta de chocolate (cuyo insumo es el cacao), y los precios mejorarían, lo que favorece a los pequeños agricultores. Puede ser mayor la ventaja si se comercializan cacaos especiales.

\section{LA COMERCIALIZACIÓN MUNDIAL DEL CACAO}

En el comercio del cacao existen dos mercados. El primero de ellos es el tradicional o de granos convencionales; el segundo corresponde al de granos especializados, en donde se manejan precios diferenciados. El primero es el mercado de los grandes volúmenes, el segundo muestra una alta tasa de crecimiento y su demanda se debe a que los granos - para los consumidores- tienen características especiales distintas a los convencionales.

En el cuadro 3, se presenta el balance de la oferta y demanda de cacao en el mercado mundial, en el período 2005-2012. En 2005/2006 se cosecharon 3,808 miles de toneladas, en 2011/12 se alcanzó la cifra de 3.990 miles de toneladas; entre ambos períodos la variación es mínima. Ha habido períodos con resultados negativos como el 2006/2007 (-9.9 \%), 2008/2009 (-3.9) y 2012/2011 (-7.4 \%). En 2010/2011 se alcanzó una cifra récord de producción, gracias a las condiciones del clima que favorecieron el desarrollo de la cosecha en los países de África, la mayor región productora de cacao al nivel mundial.

Cuadro 3. Balance de la oferta/demanda global de cacao en el mercado mundial

\begin{tabular}{|c|c|c|c|c|c|c|c|}
\hline \multirow[b]{2}{*}{ Año } & \multicolumn{4}{|c|}{ Miles de toneladas } & \multirow{2}{*}{$\begin{array}{c}\text { Excedente / } \\
\text { déficit }\end{array}$} & \multirow{2}{*}{$\begin{array}{l}\text { Inventarios } \\
\text { totales al final } \\
\text { de la estación }\end{array}$} & \multirow{2}{*}{$\begin{array}{c}\text { Ratio Inventario/ } \\
\text { molienda \% }\end{array}$} \\
\hline & $\begin{array}{c}\text { Cosecha } \\
\text { bruta }\end{array}$ & $\begin{array}{c}\text { Var. } \\
\text { Anual \% }\end{array}$ & Molienda & $\begin{array}{c}\text { Var. } \\
\text { anual\% }\end{array}$ & & & \\
\hline $2005 / 2006$ & 3,808 & 12.7 & 3,522 & 4.1 & +248 & 1,892 & 53.7 \\
\hline $2006 / 2007$ & 3,430 & -9.9 & 3,675 & 4.3 & -279 & 1,613 & 43.9 \\
\hline $2007 / 2008$ & 3,737 & 9.0 & 3,775 & 2.7 & -75 & 1,538 & 40.7 \\
\hline $2008 / 2009$ & 3,593 & -3.9 & 3,531 & -6.5 & +26 & 1,564 & 44.3 \\
\hline 2009/2010 & 3,635 & 1.2 & 3,731 & 5.7 & -132 & 1,432 & 38.4 \\
\hline 2010/2011 & 4,309 & 18.5 & 3,923 & 5.1 & +343 & 1,775 & 45.2 \\
\hline $2011 / 2012$ & 3,990 & -7.4 & 3,993 & 1.8 & -43 & 1,732 & 43.4 \\
\hline
\end{tabular}

Fuente: Tomado de ICCO $(2012$, p. 30)

El consumo mundial del cacao, medido en forma de moliendas de cacao en grano por la industria, en los últimos tres períodos analizados tiene un comportamiento positivo, sin embargo, en el período 2008/2009 presenta un crecimiento negativo 
(-6.5\%), momento en que el consumo se contrae como consecuencia de los problemas económicos mundiales y del incremento de los precios del cacao en grano. En lo que corresponde a los precios, en el largo plazo se observa, en el cuadro 4, un incremento significativo de los mismos.

\section{Cuadro 4. Precios Internacionales del cacao}

\begin{tabular}{|c|c|c|c|c|c|c|c|c|c|c|c|}
\hline & \multicolumn{3}{|c|}{ Precio diarios ICCO } & \multicolumn{3}{c|}{$\begin{array}{c}\text { Precios diarios ICCO en términos } \\
\text { constantes 2010/2011 }\end{array}$} & \multicolumn{3}{c|}{ Ratio precio producto } \\
\cline { 2 - 15 } Año & $\begin{array}{c}\text { SDRs/ } \\
\text { Ton }\end{array}$ & Var. \% & $\begin{array}{c}\text { US\$ / } \\
\text { Ton }\end{array}$ & Var. \% & $\begin{array}{c}\text { SDRs/ } \\
\text { Ton }\end{array}$ & Var \% & $\begin{array}{c}\text { US\$/ } \\
\text { Ton }\end{array}$ & Var. \% & Manteca & $\begin{array}{c}\text { Pol } \\
\text { vo }\end{array}$ & $\begin{array}{c}\text { Combi- } \\
\text { nado }\end{array}$ \\
\hline $2005 / 2006$ & 1,068 & 1.8 & 1,557 & -0.9 & 1,180 & -1.3 & 1,732 & -4.4 & 2.65 & 0.80 & 3.45 \\
\hline $2006 / 2007$ & 1,226 & 14.9 & 1,854 & 19.1 & 1,325 & 12.3 & 2,015 & 16.3 & 2.79 & 0.65 & 3.44 \\
\hline $2007 / 2008$ & 1,573 & 28.2 & 2,516 & 35.7 & 1,636 & 23.5 & 2,618 & 29.9 & 2.87 & 0.66 & 3.42 \\
\hline $2008 / 2009$ & 1,707 & 8.5 & 2,599 & 3.3 & 1,777 & 8.6 & 2,713 & 3.6 & 2.48 & 0.73 & 3.20 \\
\hline $2009 / 2010$ & 2,115 & 23.9 & 3,246 & 24.9 & 2,173 & 22.3 & 3,332 & 22.8 & 1.93 & 1.35 & 3.27 \\
\hline $2010 / 2011$ & 1,969 & -6.9 & 3,105 & -4.4 & 1,969 & -9.4 & 3,105 & -6.8 & 1.48 & 1.71 & 3.19 \\
\hline $2011 / 2012$ & 1,549 & -23.4 & 2,405 & -23.8 & 1,510 & -26.2 & 2,342 & -26.7 & 1.10 & 1.92 & 3.02 \\
\hline
\end{tabular}

Notas:

SDR: Por sus siglas en Inglés Special Drawing Rigths -Derechos Especiales de Giro- la moneda del Fondo Monetario Internacional utilizada como activo virtual de financiación y reserva internacional.

US\$S: Dólares de los Estados Unidos de América

ton: Tonelada

\section{Fuente: Tomado de ICCO $(2012$, p. 31)}

La producción mundial de cacao es absorbida principalmente por 3 países (60 \% de las importaciones), siendo Suiza el mayor importador (29.4 \%), seguido de Estados Unidos (16.7 \%) y Alemania con $13.9 \%$. La mayor parte de las exportaciones, de acuerdo con Nadurille (2010, p. 4) seguirá siendo de cacao en grano, aúnque hay intentos de los países productores en añadir más valor. Ocampo, Ríos y Soria (2012, p. 18) manifiestan que "dentro de 20 años, el cacao podría ser tan escaso, que convierta al chocolate en un carísimo producto de lujo". "El chocolate auténtico será dentro de dos décadas un carísimo y escaso producto que hará honor a su origen: Theobroma cacao, "el alimento de los dioses"".

La importancia de los procesos de asociación de productores y búsqueda de actores del comercio justo hacen sostenible su participación en un mercado con potencialidad. Según Ocampo, Ríos y Soria (2012, p. 21): 
Es importante revisar el comportamiento de los mercados, de los compradores, de los consumidores. El mercado del cacao una de sus características es ser variable además de evolucionar constantemente, esto a que los consumidores buscan experiencias con nuevos productos, lo que provoca que las empresas creen nuevas tendencias y también tienen la necesidad de aplicar nuevas estrategias y tecnología.

En la búsqueda de nuevos mercados, de las variaciones que se exponen como novedosas, en función de los consumidores finales, es que se debe consolidar una estrategia de mercados diferenciados, que son demandantes o segmentos de mercado que están a la búsqueda de condiciones especiales en los insumos (en el caso del cacao). Estos mercados permiten que los productores tengan beneficios adicionales, pero para acceder a ellos se tienen que superar los requerimientos de este tipo de demandantes. Los principales segmentos del mercado de cacao especial en el mundo son los siguientes:

- Los cacaos finos de aroma son la base del chocolate gourmet. El cacao fino se origina típicamente de árboles criollos o trinitarios, y depende de procesos apropiados para alcanzar los estándares adecuados de calidad. No existe un criterio único para aceptar que el cacao de determinado origen se pueda clasificar como cacao fino de aroma. Los responsables de evaluar la calidad del cacao otorgan o retiran puntos según sus propios criterios, los cuales no son reflejados de manera objetiva. Los compradores basan sus decisiones en el grado de fermentación y el origen genético del grano.

El precio del cacao fino de aroma es independiente del precio mundial cotizado en las Bolsas de Londres y Nueva York. Los contratos se negocian directamente entre el productor y el comprador, y dependen mucho de la calidad relativa de los granos, de su reputación en el mercado del chocolate gourmet y de su origen o singularidad. El origen del cacao le da un valor adicional que influye en la fijación de precios.

- La agricultura orgánica es un sistema de producción que mantiene y mejora la salud de los suelos, los ecosistemas y las personas. Se basa fundamentalmente en los procesos ecológicos, la biodiversidad y los ciclos adaptados a las condiciones locales, sin usar productos que puedan afectar la salud de las personas. Los productos agrícolas orgánicos son aquellos producidos en parcelas donde se evita el uso de fertilizantes y agroquímicos sintéticos, y donde se prepara la tierra con abonos durante un período de más de dos años antes de la siembra o plantación, y más de tres años antes de la primera cosecha, en el caso de los cultivos perennes. 
- El cacao con el sello de desempeño social tiene por objetivo principal garantizar la mejora de las condiciones comerciales y asegurar los derechos de los pequeños productores y trabajadores marginados. Es reconocido mundialmente como fairtrade (comercio justo) y patrocinado por la Fairtrade Labelling Organizations International (FLO), que apoya la inversión social en los procesos de desarrollo en las comunidades productoras. Las características principales de este mercado son las relaciones directas entre los compradores y proveedores, con un precio base fijo que protege a los productores cuando caen los precios mundiales.

- Además de las certificaciones de comercio justo y orgánico, existen otras certificaciones disponibles para lograr mayores beneficios para los productores de cacao. Alianza para Bosques y UTZ son los dos sistemas de certificación con mayor crecimiento en el sector cacao debido a compromisos a gran escala con empresas como Mars y Kraft.

\section{LA CADENA DEL CACAO EN EL PERÚ}

La producción del cacao está estrechamente relacionada con las condiciones medioambientales de la zona donde se cultiva. Los factores climáticos influyen en la producción de una plantación; por lo tanto, las condiciones térmicas y de humedad deben ser satisfactorias para el cultivo por ser una planta perenne. Así, su período vegetativo como la época de floración, brote y cosecha está regulado por el clima. Esta relación entre estacionalidad climática y periodo vegetativo permite establecer calendarios agroclimáticos de producción y cosecha.

La producción de chocolate basada en árboles de gran rendimiento origina que la producción de árbol criollo sea limitada, lo que sumado a la calidad de su fruto le da ventaja sobre las demás variedades en lo que corresponde a su precio. Esto que parece una debilidad se debe considerar una fortaleza, que debe ser aprovechada en la comercialización internacional. Para lograr un producto competitivo, diferenciado, debe ser considerada la integración de los diferentes eslabones de la cadena agro-productiva, donde todos son importantes. El Ministerio de Agricultura (2006, p. 22) identifica cuatro eslabones de la cadena agroproductiva del cacao, los que pueden observarse en el gráfico 2 y que a continuación se detallan:

- Eslabón productivo y de servicios de apoyo a la producción. Participan los productores cacaoteros que conducen sus unidades productivas. Intervienen agentes económicos como proveedores de insumos, asistencia técnica, equipos y maquinaria, servicios financieros (formales e informales), certificación y transporte. 
- Eslabón de industrialización (transformación). Constituye el más importante y más complejo eslabón. La información estadística acerca de este eslabón es limitada. A partir del procesamiento del grano de cacao se obtienen productos intermedios (licor o pasta de cacao, manteca, polvo de cacao) y productos elaborados (chocolates y otros productos afines como bombones, y bebidas chocolatadas).

- Eslabón de comercialización. Intervienen principalmente las organizaciones de productores y acopiadores de empresas industriales que muchas veces distorsionan los precios. Sus conceptos de calidad y apreciación están sujetos a la variedad de cacao.

- Eslabón de consumidores. Intervienen diferenciadamente los que utilizan en el tramo final de la cadena la amplia gama de productos intermedios y finales que resultan del procesamiento y/o industrialización: licor de cacao, manteca de cacao, cacao en polvo, y chocolate.

Los eslabones deben considerar las tendencias de la industria mundial del cacao y derivados, con una participación activa que permita el bienestar de los productores y satisfacer sus necesidades, proteger el medio ambiente, procurar el desarrollo social y económico de la comunidad, así como una relación armoniosa con los compradores del cacao como insumo y compradores del chocolate de modo que se logre una producción balanceada, tal como lo expone Santa Cruz (2008, p. 13):

- Considerando a los productores de cacao, "la producción seguirá creciendo en economías de pequeños productores, se requiere una menor concentración regional en vista de la gran dependencia actual de África del Oeste".

- $\quad$ Por el lado de los fabricantes de chocolate: "volúmenes crecientes basados en mercados emergentes, valor basado en mercados desarrollados". Los procesadores de cacao evalúan la "producción a gran escala versus procesos integrados en busca de balance y países de origen continúan e incrementan la molienda".

- En lo que corresponde a comerciantes de cacao "se espera crecimiento en ingredientes basados en cacao, evolución de los flujos de comercio en función de cubrir necesidades de la cadena de provisión".

Los eslabones que se citan deben estar integrados y tener la suficiente capacidad de cooperación para superar los problemas cíclicos de la producción de cacao. Habrá cambios climáticos que afecten su producción; asimismo, habrá volatilidad en los precios, tecnificación insuficiente, enfermedades y plagas del cacao que llevan 
a la reflexión y el análisis acerca de cómo se pueden superar estos problemas. Los eslabones deben protegerse entre ellos, asegurando un producto de acuerdo con los estándares de los demandantes. La decisión más importante es asumir si se considera actuar en un mercado de gran volumen o en un mercado especializado, en donde las exigencias son mayores, pero los beneficios van en esa dirección.

Grafico 2: Flujograma de la cadena agroproductiva de cacao en el Perú

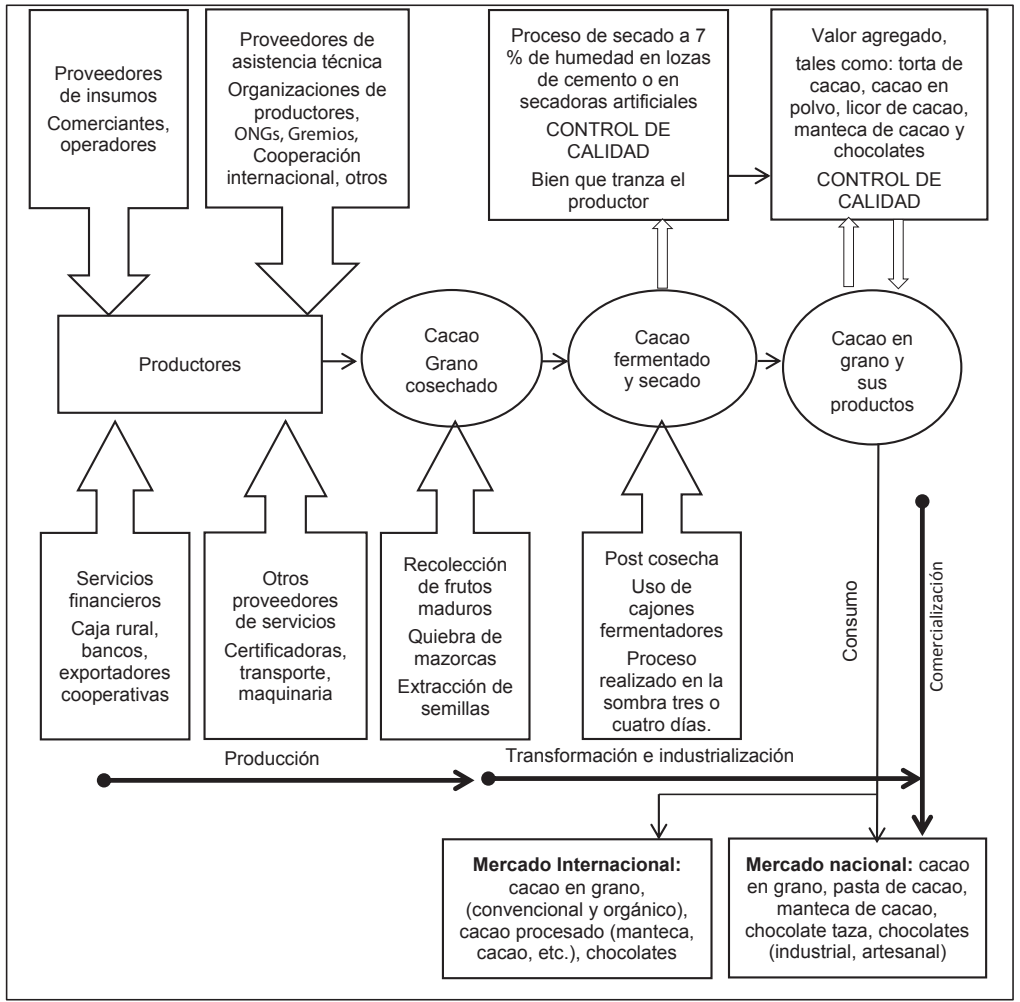

Fuente: elaboración propia con base en el Ministerio de Agricultura (2006, p. 8)

En el cuadro 5 se observa que la producción de cacao se ha duplicado en el período de análisis. En el 2005 la producción fue 25.3 m t m, en el año 2012 se produjeron $57.9 \mathrm{~m} \mathrm{t} \mathrm{m}$. El crecimiento fue de $128.9 \%$. El cacao es un producto de reciente importancia en la economía exportadora nacional. Es una opción para las familias productoras, lo que coincide con la creciente demanda de cacao especial para la elaboración de chocolates gourmet, teniéndose la posibilidad de abastecerlos, pues existe producción con características particulares que despierta el interés de procesadores extranjeros, quienes ya lo están utilizando como insumo de chocolates finos. 
Pedro Barrientos Felipa

Cuadro 5. Producción de principales productos agrícolas de exportación en Perú 2005-2012 (miles de toneladas métricas)

\begin{tabular}{|l|c|c|c|c|c|c|c|c|}
\hline \multicolumn{1}{|c|}{ Producto } & 2005 & 2006 & 2007 & 2008 & 2009 & 2010 & 2011 & 2012 \\
\hline Café & 188.6 & 273.2 & 226.0 & 273.8 & 243.5 & 279.2 & 327.9 & 304.1 \\
\hline Caña de azúcar & $6,304.1$ & $7,245.8$ & $8,228.6$ & $9,396.0$ & $9,936.9$ & $9,857.9$ & $9,884.9$ & $10,369.3$ \\
\hline Maíz A. Duro & 999.3 & $1,019.8$ & $1,122.9$ & $1,231.5$ & $1,273.9$ & $1,283.6$ & $1,260.1$ & $1,395.7$ \\
\hline Algodón Rama & 207.3 & 213.4 & 215.4 & 167.4 & 96.0 & 63.8 & 122.0 & 111.3 \\
\hline Espárrago & 206.0 & 260.0 & 284.1 & 328.4 & 313.9 & 335.2 & 392.3 & 415.9 \\
\hline Uva & 169.5 & 191.6 & 196.6 & 223.3 & 264.4 & 280.5 & 296.9 & 359.6 \\
\hline Aceituna & 54.6 & 52.5 & 52.4 & 114.4 & 7.2 & 75.0 & 73.1 & 92.5 \\
\hline Mango & 235.4 & 320.3 & 294.4 & 322.6 & 167.0 & 454.3 & 351.9 & 167.5 \\
\hline Cacao & 25.3 & 31.5 & 31.4 & 33.7 & 36.8 & 46.6 & 49.7 & 57.9 \\
\hline Palta & 103.4 & 113.3 & 121.7 & 136.3 & 157.4 & 184.4 & 213.7 & 250.3 \\
\hline Palma Aceitera & 199.9 & 236.4 & 238.4 & 246.4 & 268.3 & 291.8 & 359.8 & 518.3 \\
\hline Marigold & 122.7 & 53.7 & 21.6 & 9.6 & 6.8 & 7.3 & 23.6 & 41.9 \\
\hline Orégano & 5.7 & 6.1 & 7.2 & 9.6 & 11.2 & 11.4 & 12.1 & 11.5 \\
\hline Té & 4.2 & 4.8 & 3.6 & 4.0 & 3.2 & 3.2 & 3.2 & 3.4 \\
\hline
\end{tabular}

Fuente: Tomado de BCRP (2012) Anexo 13

En el grupo de cacaos especiales se encuentran los mercados finos de aroma, que tienen las siguientes características con respecto al cacao corriente.

- Cacao fino de aroma, que se caracteriza por la intensidad de su fragancia (floral, herbal, clavo de olor, canela, u otro), individual o combinada, y que se percibe por el olfato.

- Cacao fino de aroma y sabor, caracterizado por la intensidad de su fragancia (floral, herbal, clavo de olor, canela u otro), combinada con la intensidad de su sabor (frutas nueces, panela / malta, u otro), y perceptible a través de los sentidos del olfato y del gusto.

- Cacao fino de aroma o sabor. Aquel que sobresale ya sea por la intensidad de su aroma o por la intensidad de su sabor.

En el esfuerzo por desarrollar los cacaos finos y de aroma se ubica el trabajo que realiza la Alianza Cacao Perú, que es una iniciativa privada que busca desarrollar 
este tipo de producción como cultivo alternativo a la hoja de coca en la selva peruana. Su meta se expone en el artículo publicado en Gestión-e (2013), y es brindar asistencia técnica para implementar 28 mil ha, en los próximos años, incluyendo a 15 mil productores. Acerca de sus intenciones, el director ejecutivo de la Alianza Cacao Perú, José Iturrios, dice que lo que se busca con este proyecto es

[...] que el Perú esté en el mapa de cacaos finos y de aroma. Esto significa, que entre otras cosas, rescatar variedades que solo existen aquí, y expandir su volumen para llevarlas comercialmente a EE. UU., Europa y otros mercados emergentes como China.

Santa Cruz (2008, p. 5) referencia la clasificación comercial del cacao, de acuerdo con el convencionalismo del Centro de Comercio Internacional UNCTAD/GATT, 1991, explicando, además, que la oferta mundial de cacao fino o de aroma es relativamente reducida y representa el $5 \%$ del cacao producido en el mundo. Expone que el cacao se clasifica en

a) Cacao Ordinario: granos producidos por los cacaos tipo forastero; estos son utilizados en la fabricación de manteca de cacao y de productos que tengan una elevada proporción de chocolate.

b) Cacao fino o de aroma: en general, los granos de cacaos criollos y trinitarios corresponden a lo que en el mercado se conoce como cacao fino o de aroma. Se utiliza, usualmente, en mezclas con granos ordinarios o forastero para producir sabores específicos en productos terminados. Los granos de cacao fino dan características específicas de aroma o color de chocolates finos de revestimientos o capas de cobertura.

\section{LOS PRINCIPALES ACTORES EN LA CADENA DE VALOR DEL CACAO PERUANO}

En el ámbito internacional, la producción de cacao peruano recién está asumiendo un rol importante en la economía agraria. De acuerdo con la ICCO (2012), la producción de Perú representaba menos del $1.0 \%$ del total mundial. Esta cifra, en el mediano plazo, puede mejorar, considerando que se observa la relativa facilidad para establecer relaciones comerciales con importadores por parte de productores locales. En ocasiones, la demanda para el cacao supera la capacidad de los productores.

En la actualidad existe un esfuerzo mancomunado de compradores, productores y otras organizaciones públicas y privadas que incentivan el cultivo del cacao. Esto ha originado una cadena de valor que permite a los productores obtener buenos precios, mejorando la calidad de la producción con una orientación al consumidor internacional. Esto forma parte de su ventaja competitiva; así lo plantea Cravens y Piercy (2007, p. 271): 
Una cadena de valor es un grupo de organizaciones en una estructura vertical, que añaden valor a un bien o servicio, pasando de previsiones básicas a productos acabados para usuarios finales, que pueden ser organizaciones o consumidores particulares. Las elecciones estratégicas de las opciones de la cadena de valor son una parte importante de la estrategia orientada al mercado. La cadena de valor (red) es la configuración de los canales de distribución que vinculan a los miembros de la cadena de valor con los usuarios finales. Los canales de distribución son una cuestión central en la gestión de la cadena de valor. Un canal de distribución eficaz y eficiente ofrece a las organizaciones una importante ventaja estratégica sobre los canales competidores.

\section{Cuadro 6. Los actores en la producción de cacao}

\begin{tabular}{|c|c|} 
MINISTERIO DE AGRICULTURA \\
Dirección General de Promoción Agraria \\
Dirección General de Información Agraria \\
Oficina General de Planificación Agraria \\
Servicio General de Sanidad Agraria - SENASA \\
Instituto nacional de Recursos Naturales - INRENA \\
Programa Especial de Titulación de Tierras - PETT \\
Programa Nacional de Manejo de Cuencas Hidrográficas y Conservación de Suelos - \\
PRONAMACHS & $\begin{array}{c}\text { Innovación y competitividad para el Agro Peruano - INCAGRO } \\
\text { Programa para el Desarrollo de la Amazonía - PROAMAZONIA }\end{array}$ \\
Proyecto Especial de Promoción de Aprovechamiento de abonos provenientes de Aves \\
marinas - PROABONOS
\end{tabular}

Fuente: elaboración propia con base en el Ministerio de Agricultura (2006)

El 80 \% de las exportaciones de cacao está relacionado con la manteca de cacao y otros productos que no requieren insumos de alta calidad. Tal como expone Santa Cruz (2008, p. 16), la exportación en grano es reciente, y trabajar en su producción y su exportación implica una mayor exigencia en cuanto al origen del grano (nativo que se caracteriza por ser aromático o con características especiales/ 
diferenciadas de sabor y/o color), considerando las exigencias de los compradores. Es en esta perspectiva, que debe considerarse el consumo mundial de chocolate; hay un incremento de la demanda del cacao, porque hay nuevos consumidores, no solo en países de Europa o Norteamérica, sino que está ocurriendo en los países emergentes, en los cuales el ingreso personal mejora.

Los agentes funcionan como un canal de abastecimiento y un canal de distribución; todos ellos forman parte de una alianza estratégica. Peng (2012, p. 381) considera que los actores de la cadena de valor son socios que intercambian, comparten y desarrollan en conjunto productos, tecnologías y servicios. Puede ser una alianza contractual, que es lo que está llevándose a cabo en el Perú, pero esta requiere de compromisos basados en normas legales, que no implican compartir la propiedad.

\section{LAS CARACTERÍSTICAS DE LA PRODUCCIÓN LOCAL}

El Ministerio de Agricultura (2006, p. 22) expuso que las principales características de los productores son las que a continuación se presentan, algunas de las cuales están siendo fortalecidas por los otros agentes de la cadena de valor:

- La mayoría de los productores de cacao son pequeños productores con menos de 5 ha.

- La mayoría de la producción se realiza de manera individual. La organización es débil. Se estima que un $70 \%$ de productores no están organizados y el resto pertenece a algún tipo de organización. Está en proceso de fortalecimiento la Asociación Peruana de Productores de Cacao (APPCACAO).

- El manejo del cultivo se hace principalmente con tecnología tradicional, sin asistencia técnica.

- Los niveles de tecnología son heterogéneos y no corresponden en algunos casos a las condiciones naturales de la zona. En consecuencia, en las zonas marginales hay predominio de cacao criollo por la falta de asistencia técnica para incentivar la siembra de cacao mejorado como el clon CCN-51.

- La atomización y fragmentación de la propiedad no permite aprovechar economías de escala.

- En su mayoría, los productores no manejan costos de producción y no tienen conocimiento de estándares a cumplir.

- Asimismo, los productores tampoco tienen acceso a información sobre precios. 
- La mayoría de productores no tiene acceso a crédito adecuado para el manejo de su unidad productiva.

- Presentan serias deficiencias en los procesos de poscosecha del cacao con inadecuadas prácticas de secado y fermentación, que influyen en la calidad del grano.

¿Por qué el cacao peruano es un tema importante? En el ámbito internacional, las exportaciones peruanas no son muy importantes. Sin embargo, desde 2002 hay una fuerte demanda para el mercado peruano; esto se observa en la relativa facilidad para establecer relación con importadores por parte de algunas organizaciones de productores. La demanda para el cacao muchas veces rebasa la capacidad con que cuentan los productores, por lo que se ven obligados a incrementar drásticamente el número de socios. De acuerdo con Herrera (2012, p. 7) las razones son las siguientes:

- Es una producción amigable con el medio ambiente.

- Se puede asociar y generar ingresos económicos mientras se empieza a producir.

- Ocupa la mano de obra familiar sin grandes esfuerzos físicos.

- Hay una respuesta eficiente al manejo tecnológico.

- Permite trabajar en alianzas estratégicas.

- Existe potencial para seguir creciendo.

- Cuenta con mercado.

- Es rentable.

La tendencia es que los importadores están interesados en establecer contactos con las organizaciones, y efectuando sus transacciones comerciales a través de exportadores. Como ya se ha visto, existen dos tipos de mercado, el genérico para la industria nacional, que no requiere insumos de alta calidad para sus procesos, y el de especialidad o nichos de mercado en el extranjero, que compran grano de cacao seco para procesarlo allá bajo recetas de chocolates finos, como son los bitter $^{2}$ y los de orígenes y sabores específicos.

\section{EL CACAO EN LA ESTRATEGIA NACIONAL}

De lo expuesto se puede concluir que existen posibilidades favorables para que el cacao peruano obtenga una mayor importancia en el mercado del cacao diferen-

2 Es el chocolate propiamente dicho, pues es el resultado de la mezcla de la pasta y manteca del cacao con azúcar 
ciado, lo que está influido por los cambios en los patrones de consumo o mayores exigencias de los consumidores de chocolate, lo que deriva, a su vez, en una mayor demanda por granos especiales. La estrategia nacional se relaciona a impulsar con mayor ímpetu este tipo de mercado. La estadística expone que no se aborda el problema de producción por volumen producido sino por calidad (diferenciada) del grano. En ese sentido, es importante la opinión del especialista peruano Manuel Ríos $^{3}$ quien plantea lo siguiente:

La demanda mundial del cacao ha crecido es cierto para nuestro país, pero no necesariamente por problemas de los principales países ofertantes sino porque nosotros estamos dando a conocer el producto como cacao peruano...

Es decir, se está generando una producción desde las posibilidades del Perú, aprovechando una ventaja que tiene el grano local. Hay una acción de emprendimiento internacional, al nivel de Estado, que tiene como una arista la lucha contra el narcotráfico. Peng (2012, p. 300) define este tipo de emprendimiento como "una combinación de comportamiento innovador y proactivo y de búsqueda de riesgos que cruza las fronteras nacionales y que se pretende que genere la riqueza en las organizaciones".

El análisis inicial corresponde al escenario en que se desarrolla el producto y ahí cabe el análisis que hace el Ministerio de Agricultura (2006), basándose en el examen de fortalezas, oportunidades, debilidades y amenazas (Analisis FODA), cuyos resultados se exponen en los cuadros 7 y 8 . Son estos hallazgos, propios del análisis que se efectúa como productor, los que influyen en la dinámica competitiva, en el diseño de la estrategia que permitirá consolidarse en los mercados objetivos.

La producción debe tener una orientación al mercado, que como exponen Cravens y Piercey $(2007$, p. 3) es una perspectiva empresarial que hace que el consumidor se convierta en el punto central de las operaciones totales de la empresa. Para que esto se cumpla las organizaciones empresariales peruanas y los organismos públicos peruanos deben recopilar información acerca de los consumidores, los países productores de cacao y las oportunidades de mercado. Las decisiones deben estar enfocadas en cómo se va a ofrecer un valor superior al consumidor, comenzando por los compradores iniciales (acopiadores), y así tener el emprendimiento de otorgar valor.

El diseño de un buen producto comienza estableciendo protocolos o procesos de cómo hacer mejor las cosas. El documento del IICA (2006) es una base para de-

3 Entrevistado para los fines de este artículo. 
sarrollar de manera sólida una estrategia de penetración internacional. Se menciona en el documento que este es una guía para las instituciones que ofrecen asistencia técnica en el campo, así como un aporte para comunicarse con el productor con conceptos homogéneos, además de identificar de manera precisa áreas donde se necesita reforzar el proceso de investigación y transferencia tecnológica en el cultivo de cacao.

\section{Cuadro 7. Matriz de fortalezas y debilidades para el mercado del cacao}

\begin{tabular}{|c|c|c|}
\hline & Fortalezas & Debilidades \\
\hline $\begin{array}{l}\text { AMBIENTE } \\
\text { INTERNO }\end{array}$ & $\begin{array}{l}\text { Condiciones edafoclimáticas y } \\
\text { agroecológicas favorables. } \\
\text { Diversidad de genotipos adaptados } \\
\text { a las zonas de producción. } \\
\text { Condiciones naturales aparentes } \\
\text { para desarrollo de plantaciones en } \\
\text { sombra. } \\
\text { Generador de mano de obra princi- } \\
\text { palmente familiar que posibilita el } \\
\text { desarrollo rural. } \\
\text { Presencia de agricultores con expe- } \\
\text { riencia en el cultivo y conocimientos } \\
\text { prácticos para mejorar calidad del } \\
\text { producto. } \\
\text { Existencia de biodiversidad de } \\
\text { flora y fauna que proveen bienes y } \\
\text { servicios ambientales de gran valor. } \\
\text { Potencial sostenible de plantacio- } \\
\text { nes con sistemas agroforestales. } \\
\text { Mercado local asegurado por dis- } \\
\text { ponibilidad de capital de empresas } \\
\text { comercializadoras para compra de } \\
\text { cacao en grano. } \\
\text { Existencia de plantas para la trans- } \\
\text { formación agroindustrial. } \\
\text { Presencia de empresas familiares } \\
\text { para la transformación y generación } \\
\text { de valor agregado (chocolate para } \\
\text { taza). }\end{array}$ & $\begin{array}{l}\text { Desconfianza y desinformación para } \\
\text { organizarse. } \\
\text { Productores con limitado acceso a servi- } \\
\text { cios financieros y créditos. } \\
\text { Predominio de productores individuales } \\
\text { en micro unidades productivas, con poco } \\
\text { nivel de organización. } \\
\text { Limitada articulación e integración de ins- } \\
\text { tituciones públicas, privadas y gobiernos } \\
\text { locales. } \\
\text { Limitada infraestructura vial a centros de } \\
\text { producción. } \\
\text { Limitado empleo de plantones sanos } \\
\text { y vigorosos que provengan de viveros } \\
\text { certificados. } \\
\text { Bajos niveles de educación y adopción de } \\
\text { tecnologías mejoradas, de estándares de } \\
\text { calidad en todo el proceso, principalmente } \\
\text { en poscosecha. } \\
\text { Limitado número de productores aplican } \\
\text { manejo integrado de plagas y enferme- } \\
\text { dades. } \\
\text { Limitada infraestructura para manejo de } \\
\text { poscosecha. } \\
\text { Elevado nivel de informalidad en la comer- } \\
\text { cialización. }\end{array}$ \\
\hline
\end{tabular}

Fuente: elaboración propia con base en Ministerio de Agricultura (2006) 
La cadena de valor del cacao en Perú y su oportunidad en el mercado mundial

\section{Cuadro 8. Matriz de oportunidades y amenazas}

\begin{tabular}{|c|c|c|}
\hline & Oportunidades & Amenazas \\
\hline $\begin{array}{l}\text { AMBIENTE } \\
\text { EXTERNO }\end{array}$ & $\begin{array}{l}\text { El cacao es un sustituto importante de las } \\
\text { actividades ilícitas. } \\
\text { Arancel Preferencial Andino para ingresar } \\
\text { a Estados Unidos y países de la Unión } \\
\text { Europea. } \\
\text { Genera empleo descentralizado sobre la } \\
\text { base de uso intensivo de mano de obra. } \\
\text { Creciente interés mundial por la con- } \\
\text { servación de biodiversidad y servicios } \\
\text { ambientales. } \\
\text { Existencia de planes de capacitación } \\
\text { específicos para jóvenes. } \\
\text { Crisis social en países como Costa de } \\
\text { Marfil y Ghana. } \\
\text { Creciente segmentación de mercados } \\
\text { (orgánicos, fair trade). } \\
\text { Draw back permite sustitución de dere- } \\
\text { chos arancelarios equivalentes a } 5 \text { \% del } \\
\text { valor FOB de exportaciones. } \\
\text { Producción nacional orientada a empre- } \\
\text { sas transformadoras (agroindustria). } \\
\text { Existencia de cooperación internacional, } \\
\text { ONG, y otras instituciones que brindan } \\
\text { servicios empresariales. }\end{array}$ & $\begin{array}{l}\text { Incremento de las plagas y enfermedades } \\
\text { por la falta de control sanitario. } \\
\text { Estrategias de ventas de competidores de } \\
\text { diferenciación de productos por precios } \\
\text { antes que por calidad. } \\
\text { Uso político de agricultores en huelgas y } \\
\text { reclamos por prebendas, exoneraciones } \\
\text { y solicitud de paternalismo. } \\
\text { Inestabilidad política y social por narco- } \\
\text { tráfico y terrorismo. } \\
\text { Alta volatilidad y fluctuación de precios } \\
\text { internacionales. } \\
\text { Incremento continuo de las importacio- } \\
\text { nes. } \\
\text { Vulnerabilidad frente a fenómenos natura- } \\
\text { les y efectos del cambio climático. } \\
\text { Incertidumbre e inestabilidad en la polí- } \\
\text { tica nacional. } \\
\text { Recesión mundial y contracción de la } \\
\text { demanda de productos derivados por } \\
\text { sustitutos. } \\
\text { Creciente migración que se ubica en áreas } \\
\text { de protección forestal. }\end{array}$ \\
\hline
\end{tabular}

Fuente: elaboración propia con base en Ministerio de Agricultura (2006)

El Ministerio de Comercio Exterior y Turismo (2013) plantea que la estrategia debe ser mejorar la competitividad del cacao, en la que se deben considerar aspectos de sostenibilidad, productividad, optimización, asociatividad y altos estándares, de manera que permita una mejor actuación en el mercado. La estrategia requiere compromisos importantes, que deben ser considerados por todos los participantes, siendo su inicio el compromiso del productor. El Ministerio, como organización del Estado, expone las siguientes acciones para su logro:

- Realizar campañas de promoción del cacao peruano de alta calidad tanto al nivel nacional como al internacional, estableciendo una marca.

- Establecer convenios con brokers en Europa y EE. UU., dedicados exclusivamente a la promoción del cacao y sus derivados. 
- Establecer alianzas estratégicas y fomentar la asociatividad entre productores, agroindustriales y exportadores, promoviendo la firma de contratos de abastecimiento a largo plazo.

- Apoyar a la formación de cadenas productivas, incorporando a los pequeños productores de cacao a empresas industriales de alimentos exitosas.

- Promover la creación de empresas agroindustriales con estándares de calidad dedicadas a la transformación del cacao en zonas con potencial de desarrollo.

- Desarrollar talleres in situ sobre prevención, prospección, identificación y control de enfermedades.

- Identificar, transferir y aplicar material genético de cacao de alta productividad y tolerantes a las principales enfermedades que afectan al cultivo.

- Rehabilitar y renovar las plantaciones de cacao con clones de alta productividad y resistencia a plagas y enfermedades.

- Mejorar el manejo de poscosecha mediante un programa integral de asistencia técnica y capacitación con expertos nacionales e internacionales, articulado a través de las organizaciones de productores para su posterior divulgación a los agricultores.

- Establecer un sistema de control y certificación de calidad del grano de cacao y derivados.

- Desarrollar capacidades de liderazgo para facilitar la organización empresarial de productores.

Para que la estrategia sea efectiva, en opinión de Jain (2002, p. 500), debe ser alentada a través del establecimiento de objetivos, la capacitación de profesionales de desarrollo de la producción y de actuación en el mercado internacional, establecer los mecanismos correspondientes de comunicación entre los diferentes eslabones y tener una actitud cordial y de colaboración entre todas las organizaciones involucradas. El núcleo notable de estas acciones es la cooperación entre los productores y los compradores, que se inicia en la negociación con los acopiadores, sin ventaja para alguno de los socios o los que forman la cadena de valor. Tal como expone Barrientos (2011), el clúster puede ser aprovechado para otorgar mayor valor al producto.

\section{CONCLUSIONES}

Es innegable que los commodities tienen influencia en las economías de los países poco desarrollados como es el caso del Perú; estos representan el 75.0 \% del total 
de las exportaciones, y su rubro de mayor dinámica está en los minerales. En el mercado de los commodities agrarios, Perú participa con tres productos: algodón, azúcar y café. De los tres, es el último principalmente el que presenta un comportamiento sostenible en el tiempo. El cacao, como producto genérico, también es un commodity, pero la producción peruana no tiene relevancia en este mercado, en términos de su volumen de producción.

La producción de cacao en los países productores se identifica por que esta se realiza a través de pequeños productores. Representa la fuente de ingreso principal de 40 a 50 millones de personas en el mundo. Los principales países productores están en África, algunos de ellos presentan conflictos políticos que afectan su producción, además de los bajos márgenes por venta, lo que desanima a los cacaocultores. Los demandantes más importantes son empresas transnacionales relacionadas con la producción de chocolate, en donde el cacao es su insumo más importante. Se ubican geográficamente en Europa y Norte América. Es un mercado oligopsónico, tienen mayor poder de comercialización los consumidores que los productores. Su ventaja adicional está en el diseño de los canales de distribución, pues tienen una cadena de valor mejor que la de los productores. La expectativa del crecimiento de la industria chocolatera, que implica mayor demanda de cacao, está en el potencial de países emergentes como China e India.

El cacao tiene dos vertientes comerciales: la que se lleva a cabo a través de las bolsas de valores y aquella que se efectúa a través de cadenas independientes en la que el trato es de productor a comprador, sin la intermediación de organismo comercial alguno. En el primer mercado es donde se comercializan los principales volúmenes. El segundo es un mercado en crecimiento y está en búsqueda de cacaos diferenciados.

Los países productores de cacao están haciendo esfuerzos por disminuir la exportación en grano, promoviendo que se dé valor agregado en las comunidades locales, es decir, dentro de las fronteras nacionales. Los demandantes internacionales están otorgando incentivos para la producción de granos diferenciados, lo que posibilita que los pequeños agricultores puedan aumentar la capacidad de comercialización frente a los compradores internacionales. En este caso, el cacao peruano tiene ventajas, lo que debe ser aprovechado en beneficio de los pequeños agricultores. El futuro está en los mercados diferenciados.

El éxito del cacao peruano está en la formación de cadenas de valor, considerando que todos los eslabones son importantes, como lo expone el Ministerio de Agricultura: eslabón productivo y de servicios de apoyo, eslabón de industrializa- 
ción (transformación), eslabón de comercialización y eslabón de consumidores. Los eslabones deben estar lo suficientemente integrados y tener la capacidad de cooperación para superar los problemas cíclicos de la producción.

Hay un creciente interés, por parte de los productores, en participar en cadenas de valor o clúster considerando la ventaja que se obtiene en el precio, pero también en lo correspondiente a servicios adicionales que mejoran la productividad. En el Perú, hay una diversidad de actores que forman parte de la cadena: Ministerio de Agricultura, Ministerio de Comercio Exterior y Turismo, Ministerio de la Producción, Presidencia del Consejo de Ministros, Asociación Peruana de Productores de Cacao -APPCACAO-, la cooperación internacional, y empresas procesadoras y comercializadores.

Lo que está ocurriendo en los países productores importantes de cacao (disminución de su producción) crea una oportunidad que puede ser aprovechada para desarrollar el cultivo de cacao en Perú, motivo por el cual se debe consolidar la estrategia que se ha planteado al respecto. Se tiene que insistir en la producción de un cacao de aroma, considerando que es el grano en el que los productores peruanos tienen ventaja en el mercado internacional. Asimismo, se deben hacer esfuerzos en la investigación de cómo mantener o mejorar el grano, así como su productividad. Se debe insistir en fortalecer la cadena de valor que asegure la compra de la producción, y sostenga la calidad del producto (grano) como una cultura de producción. La cadena de valor que se ha formado al respecto ayuda a consolidar a los pequeños productores.

\section{BIBLIOGRAFÍA}

Banco Central de Reserva del Perú- BCRP (2012). Memoria Institucional 2012. Lima: Banco Central de Reserva del Perú, 334p.

Barrientos, Pedro (2011). El clúster en la estrategia de marketing internacional. En: Semestre Económico, Vol. 14, N. ${ }^{\circ}$ 28, p. 49-66.

Castro, Pilar y Contreras, Yabed (2004). Café de especialidad: una alternativa para el sector cafetalero peruano. Lima: ESAN . En: Cuadernos de Difusión, Vol. 9, № 17, p. 61-84.

Colburn, Forrest (2009). América latina: prisionera de los commodities. En: Alajuela: INCAE Business review, Vol. 1, $N^{\circ}$ 8, p. 44-49.

Cravens, D. y Piercy, N. (2007). Marketing Estratégico. Madrid: McGraw-Hill, 590p.

De la Torre, Augusto (2011). Evitando la maldición de los recursos naturales. En Boletin Informativo Techint, N. ${ }^{\circ} 336$, pp. 9-23. 
La cadena de valor del cacao en Perú y su oportunidad en el mercado mundial

El País (2013). Lehman Brothers, se declaró en quiebra en septiembre del 2008, luego de 158 años de actividad.

[En línea], El país. [Consultado 13 de septiembre del 2013].

Gestión-e (2013). Alianza cacao Perú instalará 28 mil ha de cacao fino y de aroma en los próximos cuatro años. [Consultado 14 de diciembre del 2013].

Herrera Ramírez, Rolando (2012). El cacao en el Perú. Lima, Asociación International Cocoa Organization -ICCO- (2012). La economía cacaotera mundial: pasado y presente. Londres: International Cocoa Organization, 16p.

Instituto Interamericano de Cooperación para la Agricultura -ICCA- (2006). Protocolo estandarizado de oferta tecnológica para el cultivo del cacao en Perú. Lima, Perú.

Jain, Naresh (2002). Marketing Internacional. México D. F.: International Thomson Editores S. A., $718 \mathrm{p}$.

Jenkins, Rhys (2011). El "Efecto China" en los precios de los productos básicos y en el valor de las exportaciones de América latina. En: Revista CEPAL, Santiago de Chile, No.103, p. 77-93.

Ministerio de Agricultura (2006). Plan estratégico: Cadena agroproductiva del cacao. Lima: IICA-CICDA-GTZ, 95p.

Ministerio de Comercio Exterior y Turismo- MCET (2013). Perfil de mercado y competitividad exportadora de cacao. [En línea]. [Consultado 17 de septiembre del 2013].

Nadurille Santos, Elizabeth (2010). Cacao: cadena de valor de Costa Rica. San José: Instituto Interamericano para la cooperación en la agricultura, 25p.

Ocampo, Elsy; Ríos, Joana y Soria, Zaira (2012). La producción de cacao en México. México D. F.: Universidad Nacional Autónoma de México, 48p.

Ocampo, Leonardo (2005). El manejo óptimo de la "Enfermedad Holandesa" para Ecuador. En Revista Cuestiones Económicas, Banco Central de Ecuador, Vol. 21, No 3, tercer cuatrimestre, p. 5-46.

Peng, Mike (2012). Negocios globales. Querétaro: Cengage Learning Latinoamérica, 632p.

Santa Cruz, Víctor (2008). Análisis de la cadena de cacao en la región Piura, PIDECAFE-Dirección Regional Agraria-Gobierno regional Piura, 73p.

Svampa, Maristella (2013). "Consenso de los commodities" y lenguajes de valoración en América Latina. Buenos Aires. En: Revista Nueva Sociedad, N. ${ }^{\circ}$ 244, p. 30-47. 
